\title{
MENGAPA PHALLUS ARCA SIWA-BHAIRAWA DI PURA KĚBO EDAN MENGHADAP KE ARAH KIRI?
}

\author{
Oleh: M.M. Sukarto K. Atmodjo.
}

Di dalam makalah saya berjudul 'Betulkah Aștāsura-ratna-bumi-banten seorang raja Bali yang murka dan hina (?)" pada Seminar Sejarah Nasional ke III di.Jakarta tahun 1981, saya juga menguraikan secara singkat sebuah arca Siwa-Bhairawa yang tersimpan di Pura Kebo Edan di Bali. Makalah itu pada pokoknya membahas seorang tokoh raja Bali yang disebut Pāduka Bhațāra Şrí Asțāsura-ratna-bumi-bantěn di dalam prasasti tembaga Patapan Langgaran yang bertarikh 1259 Saka. Tetapi di dalam kitab Nâgarakrtāgama yang digubah oleh pujangga Prapan̆ca, yaitu Nyanyian 49, bait 4, disebut seorang raja Bali yang murka dan hina dan yang kenudian dikalahkan oleh bala-tentara Majapahit. Nyanyian 49, bait 4 itu nenyebut sebagai berikut:

4. muwaḥ ring sākabdeșu māsākși nabhbhi, ikang bäli nāthanya dusssila nìcchā, dinon ing bala bhrașța sakweh nāsa, ars sălwir i dusta mangdoh wisathta.

Berarti lebih kurang:

4. Selanjutnya pada tahun Saka iṣu mäsäksi nabhbhī (anak panahwaktu-mata-pusat $=1265$ Saka). 1

raja Bali yang jahat dan nista (hina),

diperangi oleh bala tentara (Majapahit) dan semua hancur

binasa,

takutlah semua pendurhaka dan pergi menjauh. ${ }^{2}$

Tuduhan Prapan̂ca yang mengatakan 'ikang bāli nāthanya dussíla nicchä" itu dibenarkan oleh sebagian sejarahwan di Bali. ${ }^{3}$ lebih-lebih setelah terbit karangan Sdr. Ktut Ginarsa berjudul ' Radja siapakah yang dimaksud Prapan̂ca "'ikang Bali nathanya duecila nica"?'" di dalam majalah Bahasa dan Budaja tahun 1956.

Sebaliknya saya menduga bahwa raja Bali tersebut sebetulnva seorang raja yang gagah berani dan menghendaki pulau Bali (Bali dwipamandala) tetap berdaulat dan merdeka serta merupakan sebuah negara yang setingkat atau sejajar dengan Majapahit (Yawadwipamandala). Karena sifat keplahlawanan dan kebaikan raja itulah maka ia disebut dengan. gelar Paduka Bhatara Sri Astasura dan juga sebagai "manikam pulau Bali"' (ratna-bumi-banten). ${ }^{4}$ Dengan demikian apabila kitab Nagarakrtagama menyebut raja Bali dengan perkataan "ikang bali natha: nya dussila niccha", hal ini disebabkan karena raja Astasura tidak mau tunduk kepada negara Majapahit. 
Nama Aș̣āsura yang berarti "'delapan orang raksasa (detia)" tersebut rupa-rupanya berhubungan dengan aliran (sekte) agama yang dianutnya, yaitu sekte Tantrāyana. Selanjutnya arca-arca besar dari batu padas yang tersimpan di Pura Kěbo Edan diduga juga berasal dari jaman pemerintahan Astāsura. Menurut pengamatan saya raja itu berkuasa (memerintah) kira-kira antara tahun 1254 Saka (1256 Saka) dan 1264 Saka. Ia raja terakhir di Bali yang merdeka, karena enam tahun setelah tarikh prasasti Patapan Langgaran (1259 Saka) Gajah Mada berhasil menaklukkan pulau Bali (1264 Saka).

Pura Kĕbo Edan terdapat di desa Pejeng, Kac. Tampaksiring, Kab. Gianyar (Bali). Perkataan Kěbo Edan berarti 'Kerbau Gila'. Di sebelah utara Pura Kébo Edan terletak Pura Pusěring Jagat yang juga menyimpan benda-benda purbakala, antara lain sebuah bejana batu (sangku Sudamala) berangka-tahun (kronogram) 1251 Saka. dan dua buah batu berbentuk phallus (lingga) dan vulva (yoni) ${ }^{6}$ Di sebelah timur-laut terletak Pura Panataran Sasih yang terkenal karena menyimpan sebuah nekara perunggu bernama 'Bulan Pejeng.'. 7 Di sebelah selatan Pura Kébo Edan terdapat Pura Arjuna Mětapa yang juga terkenal karena sebuah arca di antaranya menggambarkan Arjuna yang sedang bertapa. ${ }^{8}$

Di Pura Kěbo Edan terdapat beberapa buah arca besar menggambarkan Ganesa, arca raksasa yang membawa mangkuk tengkorak, arca kerbau (lembu) dan sebuah arca Siwa-Bhairawa setinggi lebih-kurang 3,6 meter (Lihat Gambar). Arca Bhairawa itu digambarkan menari-nari di atas mayat, kaki bersikap ălídha, ${ }^{9}$ kedua belah tangannya di atas pinggang, dan mukanya ditutup dengan topeng. Karena gerak tariannya yang hebat, maka kelaminnya (phallus) terayun keluar dari celah-celah cawatnya ke arah kiri. Di bagian ujung kelamin, yaitu di sekitar glans penis, terdapat beberapa buah bulatan yang mirip dengan lingga di Pura Pusěring Jagat. Jumlah bulatan itu mungkin 3 buah atau 4 buah. ${ }^{10}$

Seperti telah saya terangkan di atas, arca yang terdapat di Pura Kĕbo Edan tersebut rupa-rupanya berasal dari jaman pemerintahan raja Asțāsura-ratna-bumi-bantěn. Jadi berasal dari sekitar pertengahan abad ẌIV Masehi. Tetapi Stutterheim mengatakan bahwa arca-arca dari Pura Kěbo Edan berasal dari abad XIII Masehi. Selanjutnya penduduk di daerah Gianyar menghubungkan arca Siwa-Bhairawa itu dengan tokoh legenda $\mathrm{Ki}$ Kěbo Iwo yang hidup pada jaman berkembangnya negara Majapahit. ${ }^{11}$ Bahkan nama Kěbo Edan pun dihubungkan dengan tokoh Kěbo Iwo., Selain itu gugusan candi-padas Gunung Kawi di Tampaksiring juga dikatakan hasil karya Kĕbo Iwo yang mengukirnya hanya dengan menggunakan kukunya. Sebuah arca kepala yang tersimpan di Pura Gaduh di Blahbatuh juga dianggap sebagai arca Kébo Iwo (Kěbo Yuwo). ${ }^{12}$

Arca Siwa-Bhairawa dari Pura Kð̌bo Edan itu bolehjadi menggambarkan raja Aștāsura sendiri. Selain itu arca bětara-bĕtari (king and queen) 
yang tersimpan di Pura Subak Taulan (sebelah barat Denpasar) yang digambarkan berdiri di atas sebelah kaki (ekapada) mungkin juga menggambarkan raja Asțāsura dengan permaisurinya. Anggapan ini berdasarkan tulisan dan angka-tahun yang terpahat di bagian belakang arca berbunyi tannana-rasa-pasek-tunggal (1260 Saka). ${ }^{13}$

Nama Aștāsura selain berarti "delapan oráng raksasa" atau "raja yang mempunyai kekuatan bagaikan delapan orang detia', mungkin dapat dibanding dengan delapan Bhairawa yang terkenal di Nepal dan menghuni kuburan (śmasāna) tertentu. Nama-nama delapan Bhairawa itu adalah:

1. Asitāngga-Bhairawa,

2. Krodha-Bhairawa,

3. Ruru-Bhairawa,

4. Kapäla-Bhairawa,

5. Unmatta-Bhairawa,

6. Saṃhära-Bhairawa,

7. Sukra-Bhairawa,

8. Bhișaṇa-Bhairawa. ${ }^{14}$

Seperti telah diketahui Bhairawa adalah bentuk krodha dewa Siwa. Tetapi juga merupakan salah satu aspek (bentuk) dewa Siwa sendiri. Sama halnya dengan Bhairawa di Nepal yang bertempat tinggal di tengah-tengah kuburan, maka Siwa-Bhairawa di Pura Kěbo Edan juga berdiri menari-nari di atas mayat. Selanjutnya arah hadap ke kiri phallus arca SiwaBhairawa Kěbo Edan mungkin berhubungan dengan aliran agama Tantrāyana yang dibedakan menjadi dua, yaitu aliran prawrtti (aliran kanan) dan aliran niwrtti (aliran kiri). Mengenai kedua aliran itu P.H. Pott mengatakan di dalam bukunya "Yoga and Yantra"' sebagai berikut:

"'Two distinct school of thought are distinguised in the Tantras. These are known as the "'right-hand" and the "'left-hand" paths. The Tantras themselves, however, do not employ this terminology but use the terms pravrtti and nivrtti. Once more, it is Avalon who has attempted to clarify the true meaning of this distinction and who has tried to dispel so much misunderstanding.

While the "right-hand path" suppresses the operation of the sense organs and in this way tries to liberate the "self" from all illusion, in the "'lefthand path" the senses are deliberately brought into contact with everything that tempts them in order to experience the relativety of this temptation and to rise above it and thus become master of it'.' 15

Berdasarkan uraian tersebut di atas sudah jelas bahwa aliran niwrtti berusaha melakukan praktek pan̂ca-ma (antara lain maithuna $=$ cinta, coitus) sebanyak-banyaknya sehingga akhirnya dapat menguasainya. Sebaliknya aliran prawrtti berusaha menekan segala keinginan atau nafsu. Rupa-rupanya raja Aștāsura (?) yang digambarkan sebagai arca Siwa-Bhairawa di Pura Kěbo Edan juga melakukan bhairawa-märgga seperti halnya raja Kṛtanāgara dari kerajaan Sif̂ghāsari. Nama Pura Kěbo Edan itu sendiri juga menunjuk ke arah praktek (perbuatan) pan̂ca-ma karena edan = māda (minum minuman keras sehingga mabuk): ${ }^{16}$ 
Sebagai penutup uraian singkat ini sekali lagi saya tekankan bahwa phallus arca Siwa-Bhairawa (Kěbo Edan) yang membelok ke arah kiri, rupa-rupanya berhubungan denga aliran niwrtti (left-hand path) yang dianut oleh raja Aștāsura (?) pada waktu itu. 17!

Sekian dan terimakasih.

Om siddhir astu.

\section{Catatan:}

1. Isu (anak panah) bernilai 5 , mäsa (waktu) 6 , akși (mata) 2 dan nabhbhī (pusat, Jawa: wuděl) 1. Kronogram (sěngkalan) itu apabila dibaca dari kanan ke kiri menunjuk angka-tahun 1265 Saka (1343 AD).

2. Teks lengkapnya lihat Th. Pigeaud: Java in the 14th Century, Translation Series 4, 1, Canto (Nyanyian) 49.

3. Jumlah sejarahwan Bali yang mengetahui Sejarah Bali Kuna tidak banyak. Mereka pada umumnya menghubungkan Astäsaura dengan tokoh Mayadānawa.

4. Bantěn = Bali (berarti kurban). Lihat M.M. Sukarto: The Charter of Kapal, hlm. 12 - 14.

5. Kronogram itu menggambarkan bulan-sabit (1), mata (2), busur (5) dan orang (1). Membacanya tetap dari kiri ke kanan (tidak dibalik) dan menunjuk tahun 1251 Saka (1329 AD).

6. Lihat karangan singkat M.M. Sukarto: La reprẻsentation phallique de la Pura Pus ering Jagat à Pejeng, Archipel 7, hlm. 127 -132.

7. Nekara itu berukuran tinggi $186 \mathrm{~cm}$ dan garis-tengah bidang yang dipukul $160 \mathrm{~cm}$. Sebuah cetakan batu tipe nekara Pejeng tersimpan di dalam pura di desa Manuaba. Lihat A.J. Bernet Kempers: Bali Purbakala, Seri Tjandi 2, Gambar No. 11 .

8. Lihat Bali Purbakala, Gambar No. 47.

9. Sikap itu disebut ningkang (bahasa Bali) atau mbrěgagah (bahasa Jawa).

10. Bernet Kempers menyebut empat buah. Lihat Bali Purbakala hlm. 59 .

11. Lihat M.M. Sukarto: Ki Kebo Iwo, Brosur No. 5 (1974) Kantor Cabang II Lembaga Purbakala dan Peninggalan Nasional, Gianyar (Bali).

12. Lihat Bali Purbakala, Gambar No. 26.

13. Berarti tidak ada rasa kesatuan di dalam pašk (golongan). Jadi menyindir suasana yang kacau menjelang serbuan Gajah Mada ke pulau Bali. Tannana (tidak ada) bernilai 0, rasa (rasa) 6, pasĕk (kelompok, golongan) 2 dan tunggal (tunggal) 1. Lihat selanjutnya M.M. Sukarto: Betulkah Aștāsura-ratna-bumi-bantěn seorang raja Bali yang murka dan hina (?), Seminar Sejarah Nasional III (setensilan).

14. Lihat P.H. Pott: Yoga and Yantra, Translation Saries 8, hlm. 82.

15. Ibid. hlm. 13.

16. Perkataan māda (minuman keras) berhubungan dengan mad (gila) dalam bahasa Inggris. Pan̆ca-ma tersebut terdiri dari: matsya (ikan), mamșa (daging), mudrā (gandum, padi-padian), māa (minuman ke- 
perbuatan maithuna terlihat bekas-bekasnya (berupa lambang phallus dan vulva) di Candi Sukuh, Cěto, gua Suci (Tuban), prasasti Samirono (Kab. Semarang), dan lain-lainnya.

17. Selesai karangan ini saya mendapat tugas melakukan survai di daerah Ponorogo, Trẻnggalek, Tulungagung dan Kédiri antara tanggal 12-3-1983 dan 17-3-1983. Selama survai saya juga melihat dua buah arca batu dengan letak phallus di sebelah kiri, yaitu:

a. Arca Bhima setinggi $155 \mathrm{~cm}$ dan sekarang terletak di halaman depan Kabupaten Trenggalek. Arca Bhima itu semula berasal dari Dukuh Ngrěco, Desa Parakan, Kac. Trĕnggalek, Kab. Trĕnggalek. Phallus Bhima itu terletak di samping kiri lipatan cawat atau kainnya (Jawa: wiron).

b. Arca raksasa jongkok (tanpa kepala karena pecah) berukuran tinggi $93 \mathrm{~cm}$ dan sekarang terletak di halaman depan Sekolah Dasar Dukuh Patik, Desa Jatimulyo, Kac. Kauman (dahulu Kalangbret), Kab. Tulungagung. Phallus arca raksasa itu sangat panjang setinggi bahu dan terletak di sebelah kiri tubuh serta dipegang dengan sebelah tangannya.

Perlu ditambahkan bahwa arca raksasa (manusia) dengan phallus juga terdapat di beberapa tempat lainnya di Jawa dan Bali, misalnya: di desa Gaprang (dekat Blitar), Candi Sukuh, punden Nglurah (dekat Tawangmangu), dan Pura Dalêm di desa Cêluk (sebelah utara Blahbatuh). Juga di daerah pedalaman Kalimantan, Sulawesi, Irian Jaya dan di pulau Nias arca telanjang berbentuk primitif dari kayu (batu) banyak ditemukan.

\section{Kepustakaan:}

Bernet Kempers, A.J.:

1956 Bali Purbakala, Seri Tjandi 2, Penerbitan dan Balai Buku Ind̄onesia, Djakarta, 1956. (disalin oleh Drs. R. Soekmono).

Ginarsa, Ktut:

1956 Radja siapakah yang dimaksud Prapanca ''ikang Bali natha. nya ducçila nica'?, di dalam majalah Bahasa dan Budaja, Th. IV, No. 5, Djakarta, hlm. 26 - 28.

Pigeaud, Th.:

1960 Java in the 14th Century, Translation Series 4, 1, The Hague, Martinus Nijhoff.

Pott P.H.:

1966 Yoga and Yantra, Translation Series 8, The Hague, Martinus Nijhoff. 
Stutterheim, W.F.:

1929 Oudheden van Bali, Publicaties der Kirtya Liefrinck-Van der Tuuk, Bali.

Sukarto K. Atmodjo, M.M:

1974 Ki Kĕbo Iwo, Brosur No. 5 (1974), Kantor Cabang II, Lembaga Purbakala dan Peninggalan Nasional, Gianyar, Bali (stensilan).

1974 La représentation phallique de la Pura Pusering Jagat a Pejeng, Archipel 7, Paris, hlm. 127 - 132.

1977 The Charter of Kapal, Aspek-aspek Arkeologi Indonesia No. 2, Jakarta.

1981 Betulkah Aștāsura-ratna-bumi-bantěn seorang raja Bali yang murka dan hina (?), Seminar Sejarah Nasional III, Jakarta (stensilan). 


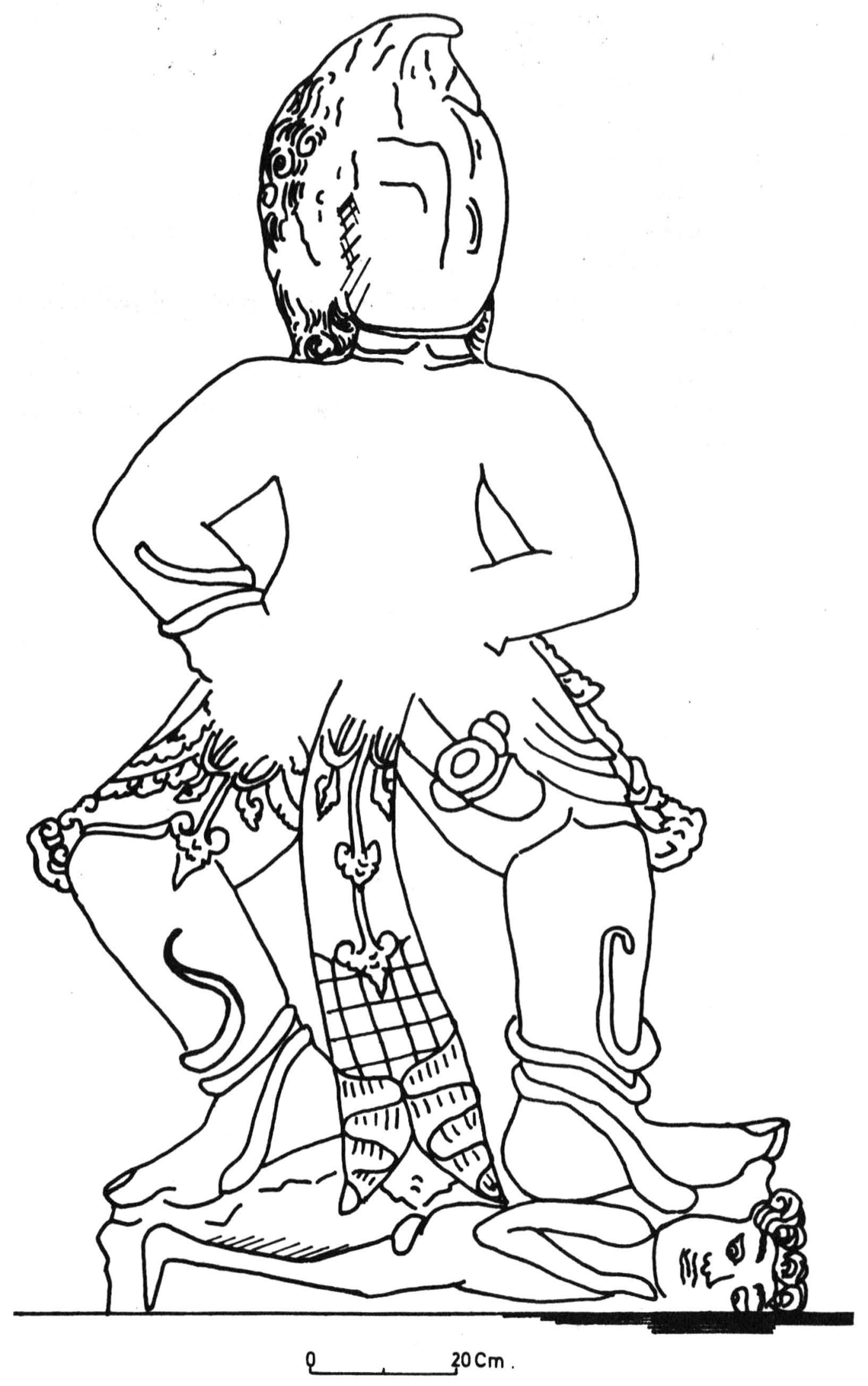

ARCA SIWA BHAIRAWA
DI PURA KE B̆O EDAN 